\title{
Esophageal fishbone impaction as a result of ingestion of "trapoen" (Surinamese dried fish)
}

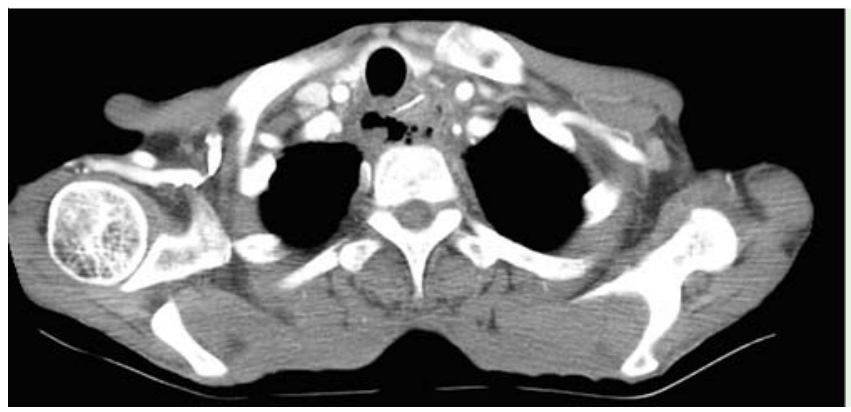

Fig. 1 A computed tomography (CT) scan of the chest in a 47-year-old man from Surinam showing a fish bone in the proximal esophagus.

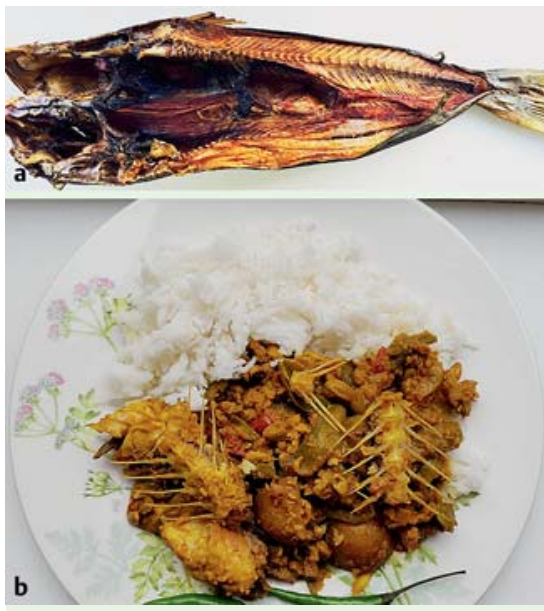

Fig. 2 Photographs showing: a "trapoen," a type of dried fish, which cannot be filleted and therefore needs to be cooked whole; b a meal made from the dried fish, which requires the flesh of the fish to be removed with the teeth as the dish is eaten.

A 47-year-old man from Surinam came to the emergency room because of a progressive burning chest pain. The pain had arisen acutely 2 days previously during dinner, increasing over time and restricting his oral intake because eating aggravated the pain.

The patient had a medical history of chronic alcoholic pancreatitis and type 2 diabetes mellitus.

Physical examination revealed an ill and confused man with fever and tachycardia. The results of laboratory tests showed elevated infection parameters, with normal hemoglobin, amylase, and bilirubin levels. A computed tomography (CT) scan of the chest was performed, revealing a surprising discovery: a foreign body in the esophagus with the density and shape of a fish bone ( $\bullet$ Fig. 1). Further question-

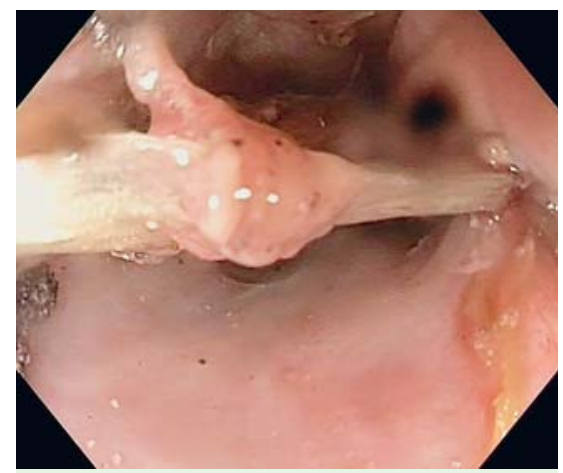

Fig. 3 Endoscopic image clearly showing the fishbone that was firmly lodged in the esophagus.

ing of the patient revealed he had eaten "trapoen" (Megalops atlanticus), a popular dried freshwater fish from Surinam (๑ Fig. 2).

Endoscopy with the patient under conscious sedation revealed a large fish bone that was bilaterally stuck in the proximal esophagus ( $\bullet$ Fig.3). A two-channel therapeutic endoscope was used, and a 15-mm CRE balloon catheter (Boston Scientific, Marlborough, Massachusetts, USA) was inserted in the first channel. The balloon was inflated distal to the fish bone, which released the bone on one side, this being accompanied by a discharge of pus. A grasping forceps (FG-44NR-1; Olympus, Zoeterwoude, The Netherlands) was inserted via the second channel to retrieve the bone, removing it whole without additional injury $[1,2]$. Because the mucosa was only mildly damaged, it was not necessary to perform an esophagogram.

The patient was subsequently treated with intravenous amoxicillin/clavulanic acid for 1 week and intravenous cefuroxime for an additional week.
The swallowing of fish bones and the injuries that occur as a consequence of this are not uncommon in Asian countries, where the consumption of fish that have more and/or smaller bones is enjoyed $[3,4]$. Though these types of fish are not frequently consumed by Europeans, many European countries have Asian diaspora and Asian foods available. Dried "trapoen" is a popular dish in the Surinamese community. Because the fish is dried, it has to be cooked whole. It is eaten by using the teeth to remove the flesh from the bone. This, combined with the loose bones present in the dish, frequently results in fish bones being swallowed.

Endoscopy_UCTN_Code_CCL_1AB_2AF

Competing interests: None

Mandhkani Mahajan', V. Manon C. W. Spaander ${ }^{2}$, J. Jan B. van Lanschot ${ }^{1}$

${ }^{1}$ Department of Surgery, Erasmus Medical Center, Rotterdam, Netherlands

2 Department of Gastroenterology, Erasmus Medical Center, Rotterdam, Netherlands

\section{References}

1 Hong KH, Kim YJ, Kim JH et al. Risk factors for complications associated with upper gastrointestinal foreign bodies. World J Gastroenterol 2015; 21: 8125-8312

2 Wang C, Chen P. Removal of impacted esophageal foreign bodies with a dual-channel endoscope: 19 cases. Exp Ther Med 2013; 6: $233-235$

3 Gharib SD, Berger DL, Choy G et al. Case records of the Massachusetts General Hospital. Case 21-2015. A 37-year-old American man living in Vietnam, with fever and bacteremia. NEJM 2015; 373: 174-183

4 Sung SH, Jeon SW, Son HS et al. Factors predictive of risk for complications in patients with oesophageal foreign bodies. Dig Liver Dis 2011; 43: 632-635

Bibliography

DOI http://dx.doi.org/

10.1055/s-0035-1569660

Endoscopy 2016; 48: E3

(c) Georg Thieme Verlag KG

Stuttgart · New York

ISSN 0013-726X

Corresponding author

Mandhkani Mahajan, MD

Department of Surgery

Erasmus Medical Center

's-Gravendijkwal 230

3015 CE Rotterdam

Netherlands

mahajanmch@gmail.com 